$71 \mid$ InterAção

\title{
A MONOCULTURA DA MENTE E 0 ETNOCÍDIO NA BACIA DO XINGU: PELA DEFESA DE UMA ECOLOGIA DE SABERES 1
}

\author{
Guilherme Pittaluga Hoffmeister ${ }^{2}$ \\ Júlia de David Chelotti ${ }^{3}$ \\ Luiz Ernani Bonesso de Araujo ${ }^{4}$
}

\section{Resumo}

O atual quadro da modernidade, marcado pela globalização, impõe inúmeros desafios à garantia e efetivação de direitos em várias esferas. $O$ presente artigo objetiva demonstrar que nesse contexto impera uma forma específica de racionalidade que tem como reflexo o extermínio de outras formas de saber e, em última medida, o massacre de etnias inteiras. Como exemplo, utiliza-se o caso do etnocídio decorrente da construção da usina de Belo Monte, na região da bacia do rio Xingu, no norte do Brasil. Desde uma abordagem complexa, o artigo também visa a refletir acerca dos limites e das possibilidades para a superação dessa racionalidade definida enquanto monocultura do pensamento por um novo paradigma. A aposta é na ideia de hermenêutica diatópica como uma forma de cosmopolitismo insurgente, e enquanto possibilitadora de uma ecologia de saberes. A partir disso, busca-se avaliar em que medida este poderia ser um caminho para a consolidação de um estado democrático de direito capaz de proteger efetivamente os direitos de populações em posição de vulnerabilidade, como, por exemplo, os segmentos indígenas.

\footnotetext{
${ }^{1}$ Artigo idealizado na disciplina Direitos da Sociobiodiversidade, ministrada pelo Prof. Dr. Luiz Ernani Bonesso de Araujo, no Programa de Pós-Graduação em Direito da Universidade Federal de Santa Maria (PPGD-UFSM), no primeiro semestre de 2016.

2 Mestre em Direito pelo Programa de Pós-Graduação em Direito da Universidade Federal de Santa Maria (PPGDUFSM), Direito na área de concentração Direitos Emergentes na Sociedade Global, linha de pesquisa Direitos na Sociedade em Rede. Graduado em Direito pela Universidade Franciscana (UFN). Graduando em Relações Internacionais pela Universidade Federal de Santa Maria (UFSM). Advogado. E-mail: gphoffmeister@gmail.com

3 Mestranda em Direito pelo Programa de Pós-Graduação em Direito da Universidade Federal de Santa Maria (PPGDUFSM). Graduada em Direito pela Universidade Franciscana (UFN). Email: julia.chelotti@gmail.com

4 Doutor e Mestre em Direito pela Universidade Federal de Santa Catarina (UFSC). Professor Associado do Departamento de Direito da Universidade Federal de Santa Maria (UFSM). Professor do Mestrado em Direito da Universidade de Passo Fundo - UPF. Professor do Programa de Pós-Graduação - Mestrado em Direito da UFSM. Líder e Pesquisador do Grupo de Pesquisa em Direito da Sociobiodiversidade (GPDS/UFSM). E-mail: Iuiz.bonesso@gmail.com
} 
Palavras-chave: Cosmopolitismo Insurgente; Ecologia de Saberes; Etnocício; Hermenêutica Diatópica; Monocultura da Mente.

\begin{abstract}
The current framework of modernity, marked by globalization, imposes numerous challenges to the guarantee and realization of rights in various spheres. The present work aims to demonstrate that in this context a specific form of rationality reigns, and has, as a reflection, the extermination of other forms of knowledge and, ultimately, the massacre of entire ethnic groups. As an example, is used the case of etnocide arising from the construction of the Belo Monte plant in the Xingu basin, region of northern Brazil. From a complex approach, the article also aims to reflect on the limits and possibilities for overcoming this rationality defined as a monoculture of thought by a new paradigm. The bet is on the idea of diatopic hermeneutics as a form of insurgent cosmopolitanism, and as an enabler of an ecology of knowledges. From this, it seeks to assess to what extent this could be a path to the consolidation of a democratic state of law capable of effectively protecting the rights of populations in a position of vulnerability, such as the indigenous segments.
\end{abstract}

Keywords: Diatopical Hermeneutics; Ecology of Knowledges; Ethnocide; Insurgent Cosmopolitanism; Monoculture of the Mind.

\title{
1. INTRODUÇÃO
}

Em um mundo a cada vez mais globalizado, a complexidade das relações que se estabelecem e que compõem o quadro da modernidade exige uma análise jurídica que transcenda a esfera analítica dogmática, ou do positivismo jurídico. A percepção das limitações da ciência jurídica diante do atual estado de coisas da modernidade é condição sem a qual não se pode avaliar concretamente os limites e as possibilidades de efetivação de direitos no plano concreto.

A lógica imperante é a de uma razão indolente que está submetida tão somente a um ideal de maximização econômica fortemente atrelada aos princípios do neoliberalismo. Nesta toada, os direitos das minorias acabam, por 
muitas vezes, sendo solapados. É o caso, por exemplo, das populações indígenas na região norte do Brasil. Mas as disputas transpassam o cariz economicista. É preciso conjugar a economia com outras dinâmicas de poder, que perpassam pela filosofia, pela história, pela cultura, dentre as inúmeras facetas da complexidade que é a marca do tempo atual.

Para Pedro Demo, as dimensões da complexidade são a dinamicidade, a não-linearidade, a reconstrução, a dialética evolutiva, irreversibilidade, intensidade e a ambivalência (DEMO, 2008, pp. 13-31). Assim, a complexidade é uma palavra que se constituiu e identifica muito mais enquanto problema do que com solução (MORIN, 2003, p. 8). Portanto, importante esclarecer que presente trabalho não possui a pretensão de alcançar conclusões incontestes, mas de contribuir na evolução da reflexão de uma questão altamente complexa, como se verá.

Nesse sentido, a primeira parte visa traçar um panorama do atual estado de coisas da modernidade, no sentido de demonstrar que a imposição de uma forma de pensar, que se dá nem sempre de uma forma evidente, é global, eurocêntrica e totalizante. Para tanto, utiliza-se da ideia de monocultura da mente introduzida por Vandana Shiva e de sua ocorrência no mundo em uma perspectiva desde as noções de globalização apresentadas Boaventura de Sousa Santos.

O segundo momento se ocupa de fazer uma análise das implicações da construção da usina hidrelétrica de Belo Monte, na bacia do Xingu, na região norte do Brasil. Desde o relato de uma Procuradora de Justiça, que trabalhou na região, busca-se demonstrar que a metáfora da destruição das ervas-daninhas e a crítica ao etnocídio e ao epistemicídio se apresenta de forma emblemática nesse caso em concreto. 
$74 \mid$ InterAção

Na parte final, apresenta-se a ideia de uma ecologia de saberes ao mesmo tempo em que se a propõe como um caminho possível a fim de mitigar os efeitos danosos da razão indolente que é a marca que baliza o pensamento moderno. Para tanto, a aposta é uma construção teórica capaz de conjugar as ideias de cosmopolitismo subalterno e hermenêutica diatópica.

\section{A GLOBALIZAÇÃO DA MONOCULTURA DA MENTE}

O presente capítulo objetiva demonstrar que o atual quadro da modernidade apresenta uma estrutura de pensamento que é mantenedora de uma lógica colonial. Isto é, opera-se uma negação dos saberes que não se adaptam as lógicas e aos interesses financeiros do norte geopolítico.

A história da modernidade, seja a partir dos seus marcos históricos ${ }^{5}$, seja pelas teorias $^{6}$ - que filosófica e cientificamente a inauguram -, projetaram uma miragem de centralidade de poder mundial para a Europa (DUSSEL, 2009). Essa foi responsável, consequentemente, por desconsiderar as descobertas e avanços dos povos não europeus - infantilizando-os e invisibilizando-os - justificando, assim, a "missão civilizadora" da colonização e a dispensabilidade da vida de alguns seres humanos. Aliás, aqui cabe atentar que, segundo Mignolo (2005) não

\footnotetext{
${ }^{5}$ Os acontecimentos históricos essenciais para a implantação do princípio da subjetividade moderna são a Reforma, a llustração e a Revolução Francesa. Como se pode observar, segue-se uma sequencia espacial-temporal: quase sempre se aceita também o Renascimento Italiano, a Reforma e a llustração alemãs e a Revolução Francesa (DUSSEL, 2005, p. 28).

6 Para muitos, Galileu (condenado em 1616), Bacon (Novum Organum, 1620) ou Descartes (0 Discurso do Método, 1636) seriam os iniciadores do processo moderno no século XVII (DUSSEL, 2005, p. 28)
} 
75 InterAção

é possível conceber a modernidade sem a colonialidade7, eis que uma é constitutiva da outra.

A modernidade surge, então, com os vínculos formados entre a racionalidade formal, o poder, a aspiração de dominação e a emergência de um mercado mundial, vínculos os quais servem de base para a noção de progresso ocidental, da superioridade do homem europeu sobre a natureza, tendo o capitalismo como um forte marco para o controle não somente dos corpos, mas do pensamento, da humanidade e da vida (WALSH, 2008, p. 136). Esse contexto deve ser levado em conta em se tratando da globalização, eis que as relações de poder dadas a partir da colonização, ao foram superadas tão logo o processo histórico foi findado.

A globalização, que potencialmente poderia propiciar um desenvolvimento mundial e uma troca efetiva de saberes, acaba por colaborar com a lógica mercadológica capaz de solapar os direitos de populações que a ela não se adaptam. Para Milton Santos (2015, p. 23), a globalização é o ápice do processo de internacionalização do mundo capitalista, e para entende-la é preciso ter em conta o estado das técnicas e o estado da política. O referido autor afirma que a história consiste no fato de as técnicas serem oferecidas como um sistema e, além disso, serem realizadas combinadamente através do trabalho e das formas de escolha dos momentos e dos lugares de seu uso.

Diante desse panorama, faz-se fundamental uma crítica ao atual estado de coisas que se depreende do processo de globalização. No plano jurídico, sobretudo, se pode observar uma série de violações e mesmo uma grande

\footnotetext{
${ }^{7}$ Segundo Aníbal Quijano, a colonialidade é um conceito que por mais que se vincule ao colonialismo, transcende a este, eis que refere-se estritamente a uma estrutura de dominação/exploração onde o controle da autoridade política, dos recursos de produção e do trabalho de uma população determinada domina outra de diferente identidade e cujas sedes centrais estão, além disso, noutra jurisdição territorial. 0 colonialismo é obviamente, mais antigo, enquanto a Colonialidade tem vindo a provar, nos últimos 500 anos, ser mais profunda e duradoura que o colonialismo. (QUIJANO, 2010, p. 84). A partir de tais lições, entende-se a colonização como um grande evento prolongado, e não como uma etapa histórica já superada.
} 
dificuldade de proteção aos direitos de populações em estado vulnerável, como os povos originários. Por essa razão, faz-se necessária uma análise crítica do panorama também através dessa lente.

Boaventura de Sousa Santos atribui a globalização a uma tensão no Estado-nação a partir da globalização, em um processo autorreferencial. O autor percebe uma erosão do Estado-nação em razão da globalização, e coloca a questão de saber se questões como a regulação social e a emancipação social deverão ser deslocadas para o nível global.

É neste sentido que já se começou a falar em sociedade civil global, governo global e equidade global. Na primeira linha deste processo, está o reconhecimento mundial da política dos direitos humanos. A tensão, porém, repousa, por um lado, no facto de tanto as violações dos direitos humanos como as lutas em defesa deles continuarem a ter uma decisiva dimensão nacional, e, por outro lado, no facto de, em aspectos cruciais, as atitudes perante os direitos humanos assentarem em pressupostos culturais específicos. A política dos direitos humanos é, basicamente, uma política cultural. Tanto assim é que poderemos mesmo pensar os direitos humanos como sinal do regresso do cultural, e até mesmo do religioso, em finais de século. Ora, falar de cultura e de religião é falar de diferença, de fronteiras, de particularismos. Como poderão os direitos humanos ser uma política simultaneamente cultural e global? (SANTOS, B., 2002, s.p.).

A questão dos direitos humanos permeia todo o trabalho, na medida em que a forma de racionalidade indolente imperante se utiliza da proposta de direitos humanos, e é ela mesma uma causa e instrumento para a violação dos direitos que defende, como se depreenderá dos capítulos seguintes. No que tange à globalização, importa referir que o autor busca compreender como se dá o fenômeno e quais as suas implicações práticas. O autor reconhece as definições de vertentes mais centradas no aspecto econômico, mas destaca a importância de se considerar os aspectos sociais, culturais e políticos. 
Compreender a globalização é uma via de mão-dupla. É necessário compreender os fenômenos dos quais decorre e também os fenômenos gerados por ela. Se por um lado existe uma classe capitalista transnacional, existe, por outro lado, classes e grupos subordinados, há trabalhadores migrantes e os refugiados, que nas três últimas décadas têm efetuado bastante movimentação além-fronteiras. Destaca-se ainda que entre os executivos das empresas multinacionais e os emigrantes e refugiados, os turistas representam um terceiro modo de produção da compressão tempo-espaço (SANTOS, B., 2002, s./p.).

É possível referir, nesse sentido, que há globalizações e globalizações. Isto é, não é prudente pensar a globalização enquanto um processo uno, ensimesmado e irreversível a partir de uma perspectiva isolada. Por essa razão, Boaventura de Sousa Santos propõe a divisão em quatro modos de produção de globalizações. Cada modo de produção de globalização gera uma forma de globalização e consequências diversas no - a partir dessa perspectiva irreversível quadro globalizado-globalizante.

O primeiro deles é o localismo globalizado, e "consiste no processo pelo qual determinado fenômeno, entidade, condição ou conceito é globalizado com sucesso" (SANTOS, B., 2010a, p. 438). Esse é o processo pelo qual se dá o reconhecimento global da hegemonia de determinado local, um exemplo é a globalização do fast food. Através desse modo de globalização se dita os termos da integração, de competição/negociação e inclusão/exclusão.

O segundo processo é o que o autor nomeia globalismo localizado. Esse consiste no "impacto específico nas condições locais das práticas e imperativos transnacionais que emergem dos localismos globalizados" (SANTOS, B. 2010a, p. 438). Isto é, trata-se do reflexo direto do localismo globalizado, é o ônus suportado por locais que se encontram em posição de vulnerabilidade em relação 
a outras localidades um exemplo é a eliminação do comércio tradicional e da agricultura de subsistência em nome de um "ajustamento estrutural".

Estes dois processos de globalização operam em conjunção, e constituem o primeiro modo de produção da globalização, a globalização hegemônica, também denominada neoliberal, globalização de cima para baixo, em suma, a versão mais recente do capitalismo e imperialismo globais. (SANTOS, B. 2010a, p. 483).

Significa dizer que o localismo globalizado e o globalismo localizado são as duas faces de uma mesma moeda. Trata-se da imposição do Norte geopolítico por sobre o Sul. Enquanto os países do Norte global especializam-se e se expandem através dos localismos globalizados, cabe aos países do Sul global o ônus de suportarem os globalismos localizados sem paridade de condições de competitividade. Esse é o sistema-mundo.

Dentro dessa mesma ótica, antes mesmo de analisar as outras formas de globalização propostas pelo autor, pode-se observar que esta lógica, que insiste em guiar o pensamento ocidental através dos séculos, é verificável também no plano normativo e, por conseguinte, afeta a proteção dos direitos humanos.

A dispersão e a multiplicidade normativas são uma realidade incontrastável dos nossos tempos atuais. As inúmeras fontes de produção do Direito nacionais e não nacionais convocam o intérprete a reconhecer tal dispersão e, no passo seguinte, perguntar-se sobre a necessidade de estabelecer-se ordenação ao múltiplo. A escassez de um mínimo de ordem conduz inevitavelmente à experiência do caos e aumenta os patamares de incerteza. Não fosse a alta complexidade que esse cenário apresenta, mais grave se mostraria essa realidade quando o que está em jogo é a aplicação e a efetivação de regras protetivas de direitos humanos. (SALDANHA, 2016, p. 147).

De fato, se a lógica é a percepção de que se deve globalizar tantos localismos quanto possíveis e, ao mesmo tempo, evitar localizar globalismos, isso se aplica também no campo normativo. De igual forma, no momento de uma 
decisão jurídica, em razão da ética e da estética globalizada neoliberal também se decidirá de acordo com os localismos. O problema que advém dessa racionalidade é o fato de que a globalização é um fenômeno em expansão e a cada vez mais diversas culturas se entrecruzam e exigem respostas mais sofisticadas, que sejam capazes de compreender os embates interculturais. Por essa razão, é preciso pensar em outras formas de globalização que permitam o avanço do pensamento também no que tange a respostas mais adequadas à proteção de direitos humanos que estão em jogo a todo momento no século XXI.

O terceiro modo de produção de globalização delineado por Boaventura de Sousa Santos se destaca enquanto uma alternativa contra-hegêmonica que pode auxiliar na busca de respostas aos problemas enumerados supra: o cosmopolitismo subalterno insurgente. Esse se manifesta enquanto resistência transnacionalmente organizada contra localismos globalizados e globalismos localizados. "Trata-se de um conjunto muito vasto e heterogêneo de iniciativas, movimentos e organizações que partilham a luta contra a exclusão e a discriminação sociais e a destruição ambiental produzidas pela globalização neoliberal (...)” (SANTOS, B. 2010a, p. 439). Ainda que o foco do autor sejam as lutas e um plano político, econômico e cultural, é possível verificar a possibilidade também de um cosmopolitismo jurídico subalterno insurgente.

O quarto processo de globalização também é contra-hegemônico e consiste na emergência de lutas transnacionais por valores, ou recursos que, pela sua natureza, são tão globais como o próprio planeta, os quais o autor referencia como patrimônio comum da humanidade, em homenagem ao direito internacional (SANTOS, B., 2010a, p. 439). Em que pese essa última vertente ser passível de críticas, sobretudo por parte do Sul global, retoma-se o destaque para as primeiras duas. 
Não há qualquer dúvida de que as violações de direitos humanos são suportadas em maior medida, no contexto da globalização, pelos cidadãos de países do Sul global, sobretudo populações vulneráveis. Uma vez que o cosmopolitismo subalterno insurgente é uma das formas de mitigar e subverter a massacrante hegemonia nortenha, é fundamental que exista um diálogo no sentido de aprimorar essa forma de cosmopolitismo que seja também jurídica. Não se deixa de registrar o paradoxo que circunda as novas tecnologias digitais, as quais ao mesmo tempo se constituem enquanto limites e possibilidades para o avanço de uma globalização hegemônica e para organização contrahegemônica frente aos desafios insurgentes. O paradoxo da evolução tecnológica consiste no fato de que "nada impede que reconheçamos e que desejemos maior progresso e, ao mesmo tempo, constatemos que obtê-lo não melhora necessariamente a qualidade de vida para a maioria das pessoas" (DUPAS, 2012, p. 14).

Ainda sobre progresso, importante destacar que, neste trabalho, se o entende na linha do que afirma Carlos Walter Porto-Gonçalves (2006, p. 62), ou seja, como parte da hegemonia cultural tecida a partir do Iluminismo e da modernidade colonial, tendo o desenvolvimento como o nome-síntese de dominação tanto da natureza, quanto do pensamento. A visão cartesiana, técnico-científica e eurocêntrica de mundo, nessa perspectiva, é responsável por legitimar uma exploração ilimitada da natureza e, mais ainda, do pensamento, ignorando, inclusive, os saberes e tradições dos povos que têm a sua cultura e a sua razão de ser a partir da sua relação com a natureza. Segundo referido autor, [...] o aparente absurdo só o é na medida em que a colonização do pensamento nos fez crer que há povos atrasados e adiantados, como se houvesse um relógio que servisse de parâmetro universal. (PORTO-GONÇALVES, 2006, p. 64).

O problema disso, segundo Vandana Shiva (2003, p. 17), é que os sistemas de saber se articulam também enquanto sistemas de poder. Segundo a autora, 
[A]s monoculturas ocupam primeiro a mente e depois são transferidas para o solo. As monoculturas mentais geram modelos de produção que destroem a diversidade e legitimam a destruição como progresso, crescimento e melhoria. Segundo a perspectiva da mentalidade monocultural, a produtividade e as safras parecem aumentar quando a diversidade é eliminada e substituída pela uniformidade. Porém, segundo a perspectiva da diversidade, as monoculturas levam a um declínio das safras e da produtividade. São sistemas empobrecidos, qualitativamente e quantitativamente. Também são sistemas extremamente instáveis e carecem de sustentabilidade. As monoculturas disseminam-se não por aumentarem a produção, mas por aumentarem o controle. (SHIVA, 2003, pp. 17-18).

A reflexão perpetrada por Shiva se dá sobretudo no plano da agricultura. Porém, vislumbra-se esse mesmo tipo de racionalidade no plano da expansão capitalista em vários níveis. Isto é, o império de uma razão indolente (SANTOS, B.; MENESES, 2010, p. 23), marcada pela colonialidade (QUIJANO, 2010, p. 84), que é reflexo do pensamento moderno, caracterizado pela separação da dupla sujeito-objeto descartiana (DUSSEL, 2009, pp. 341-354).

Nesta toada, observa-se o avanço da globalização hegemônica que, ancorada em uma forma de pensar única, colonial e monocultural, se constitui cada vez mais enquanto uma ameaça a diversas esferas de direitos e em distintos níveis. À reflexão proposta por Shiva, que se estrutura principalmente por sobre uma ótica agrícola, infere-se o equivalente humano. Isto é, o trabalho busca demonstrar que as relações de saber-poder utilizadas para deslegitimar e destruir conhecimentos que desinteressem a determinados interesses econômicos se reproduz também no que tange a relações com etnias inteiras. É o que se demonstrará no próximo capítulo. 


\section{OS ÍNDIOS TÊM ALMA? O ETNOCÍDIO NA BACIA DO XINGU COMO DESTRUIÇÃO DAS ERVAS- DANINHAS}

Este capítulo visa conjugar o conceito de fascismo epistemológico, trabalhado por Boaventura de Sousa Santos, com a ideia de destruição de ervasdaninhas introduzida por Vandana Shiva, a fim de demonstrar a forma pela qual ambas ilustram a materialização de um caso de etnocídio. Para tanto, avalia-se o panorama da construção da hidrelétrica de Belo Monte, na região da bacia do rio Xingu, no norte do Brasil, e de seus efeitos. Desde o depoimento da Procuradora da República Thais Santi - em entrevista concedida à jornalista Eliane Brum (2014), publicada no jornal El País, em 1. ${ }^{\circ}$ de dezembro de 2014 -, busca-se demonstrar que esse tipo de massacre aos povos originários no Brasil é não um ponto fora da curva, mas algo completamente coerente com a racionalidade indolente que é marca do atual estado de coisas do capitalismo na modernidade.

Diante da busca pelo progresso, lideranças políticas e grandes grupos empresariais não tergiversam: fazem o que tem de ser feito, ainda que ao arrepio da lei. A mais controversa obra do Programa de Aceleração do Crescimento (PAC), dos governos Lula-Dilma, é uma operação de mais de R\$ 30 bilhões. A construção de uma das maiores usinas hidrelétricas da América Latina tem um potencial energético fascinante. Não mais fascinante, porém, que os efeitos nefastos que carrega consigo.

Segundo Brum e Santi, o caminho planeado pelo governo para implementar a construção da usina se deu como se fosse uma prerrogativa política a de respeitar ou não a lei, o que, está claro, não é admissível. Além disso, destacam que mesmo com as - à época - 22 ações movidas pelo Ministério Público Federal, a Justiça Federal se recusava a interferir na construção, pois os magistrados consideravam que seria uma interferência por parte do poder judiciário em atos de opção governamental do executivo (BRUM, 2014, s./p.). 
Ora, é inadmissível que um juiz deixe de aplicar a lei em razão do descumprimento se dar por parte ou com o aval do governo.

No direito brasileiro, para além da proteção ao meio ambiente, o direito dos povos tradicionais é assegurado constitucionalmente. Ainda assim, em nome do progresso e de interesses vários, esses direitos são desrespeitados. Por alguma razão, o solapamento desses direitos não recebe a atenção de outros fatos sociais. O desenvolvimento exige energia e, ao que parece, a manutenção do território e do modo de vida dos povos tradicionais é algo de que o Estado brasileiro está disposto a abdicar em nome do progresso.

A história se repete. A apropriação e a violência contra os povos indígenas se repetem. Os índios têm alma? A pergunta dos humanistas dos séculos XV e XVI e respondida, à época, pelo Papa, reaparece.

Quando o Papa Paulo III respondeu positivamente na bula Sublimis Deus, de 1537, fê-lo concebendo a alma dos povos indígenas como um receptáculo vazio, uma anima nullius, muito semelhante à terra nullius, o conceito de vazio jurídico que justificou a invasão e ocupação dos territórios indígenas. Com base nestas concepções abissais de epistemologia e legalidade, a universalidade da tensão entre a regulação e a emancipação, aplicada desde lado da linha, não entra em contradição com a tensão entre apropriação e violência aplicada do outro lado da linha. (SANTOS, B., 2010b, p. 37).

Mais uma vez, o saber predominante, monocultural, sobrepuja o saber indígena. Mais uma vez em nome do progresso o avanço contra uma população indígena é justificado. Essa lógica de pensamento é muito similar à utilizada por Vandana Shiva a respeito da agricultura, em que a diversidade é vista como uma erva-daninha. A autora refere que

O ponto de vista das matérias-primas industriais é a silvicultura reducionista do capitalismo que divide a democracia e a diversidade viva da floresta em duas categorias: a madeira com valor comercial e o resto, "ervas-daninhas" e "lixo", que devem 
ser destruídos. Esse "lixo", porém, é a riqueza de biomassa que contém a água e os ciclos dos nutrientes da natureza e que satisfaz as necessidades de comida, forragem, fertilizantes, fibras e remédios das comunidades agrícolas.

Assim como a silvicultura "científica" exclui as funções de produção do alimento da floresta e destrói sua diversidade, vista como "erva-daninha", a agricultura "científica" também destrói espécies que podem ser utilizadas como alimento, apesar de não poderem ser vendidas no mercado. (SHIVA, 2003, pp. 38-39).

Assim como espécies não comercializáveis são entendidas enquanto ervasdaninhas para a silvicultura científica, a permanência de populações indígenas em áreas com potencial econômico a ser explorado é vista de forma negativa por aqueles que tem o interesse de explorar. O modus operandi colonial segue tão verdadeiro quanto há 500 anos. A globalização potencializa a manutenção de uma razão indolente que em pouco ou nada se preocupa com populações em situação de vulnerabilidade, em uma realidade em que apenas o lucro interessa. Ignora-se que “[o]s saberes locais são expressões culturais de povos tradicionais, ensinados de geração a geração como prática de vida e estão, por isso, integrados na identidade comunitária desses povos". (ARAUJO, 2010, p. 275).

Nesta toada, o saber indígena é relegado a um segundo plano. A própria existência de populações indígenas, desde a perspectiva da importância de seu modo de vida, é relativizada. À medida que a construção de Belo Monte avança, os indígenas necessitam a cada vez mais de uma proteção maior frente ao desastre ambiental que é reflexo da construção da usina. Por essa razão, o governo federal põe em prática o Plano Emergencial. Thais Santi explica que

O Plano Emergencial tinha como objetivo criar programas específicos para cada etnia, para que os indígenas estivessem fortalecidos na relação com Belo Monte. A ideia é que os índios se empoderassem, para não ficar vulneráveis diante do empreendimento. (...). Comecei a perceber o que estava acontecendo quando fiz essa visita à terra indígena de Cachoeira Seca e conheci os Arara, um grupo de recente contato. E foi um choque. Eu vi a quantidade de lixo que tinha naquela aldeia, eu vi as casas destruídas, com os telhados furados, chovendo 
dentro. E eles dormiam ali. As índias, na beira do rio, as crianças, as meninas, totalmente vulneráveis diante do pescador que passava. Quando Belo Monte começou, esse povo de recente contato ficou sem chefe do posto. Então, os índios não só se depararam com Belo Monte, como eles estavam sem a Funai dentro da aldeia. De um dia para o outro ficaram sozinhos. (...). Esse grupo de recente contato estava comendo bolachas e tomando refrigerantes, estava com problemas de diabetes e hipertensão. Mas o meu impacto mais brutal foi quando eu estava tentando fazer uma reunião com os Arara, e uma senhora, talvez das mais antigas, me trouxe uma batata-doce para eu comer. Na verdade, era uma mini batata-doce. Parecia um feijão. Eu a peguei, olhei para a menina da Funai, e ela falou: "É só isso que eles têm plantado. Eles não têm nada além disso". Esse era o grau de atropelo e de desestruturação que aquele plano tinha gerado. Era estarrecedor. (...)

Era como se fosse um pós-guerra, um holocausto. Os índios não se mexiam. Ficavam parados, esperando, querendo bolacha, pedindo comida, pedindo para construir as casas. Não existia mais medicina tradicional. Eles ficavam pedindo. E eles não conversavam mais entre si, não se reuniam. O único momento em que eles se reuniam era à noite para assistir à novela numa TV de plasma. Então foi brutal. E o lixo na aldeia, a quantidade de lixo era impressionante. Era cabeça de boneca, carrinho de brinquedo jogado, pacote de bolacha, garrafa pet de refrigerante. (...)

Tudo o que eles tinham recebido do Plano Emergencial. O Plano Emergencial gerou uma dependência absoluta do empreendedor. Absoluta. E o empreendedor se posicionou nesse processo como provedor universal de bens infinitos, o que só seria tolhido se a Funai dissesse não. A Norte Energia criou essa dependência, e isso foi proposital. E se somou à incapacidade da Funai de estar presente, porque o órgão deveria ter sido fortalecido para esse processo e, em vez disso, se enfraqueceu cada vez mais. Os índios desacreditavam da Funai e criavam uma dependência do empreendedor. Virou um assistencialismo. (...)

A Norte Energia é um provedor de bens que eles não sabem para que serve. Outra antropóloga contou que estava nos Araweté quando o Plano Emergencial chegou. Todas as aldeias mandavam suas listas, pedindo o que elas queriam, e os Araweté não tinham feito isso, porque não havia coisas que eles quisessem. Eles ficavam confusos, porque podiam querer tudo, mas não sabiam o que querer. E aí as coisas começaram a chegar. (...). Tonéis de refrigerante, açúcar em quantidade. Foi assim que aconteceu. Este era o Plano Emergencial. (BRUM, 2014, s./p.). 
O Plano Emergencial, que deveria servir, em teoria, para proteger os povos tradicionais, acabou tendo o efeito inverso. Tal qual o escambo realizado no século XVI, o Plano Emergencial deu às tribos do Xingu um sem número de quinquilharias com ares de sofisticação e alimentos prejudiciais à saúde. O efeito não poderia ser diverso: aos poucos as tribos se foram dispersando, longe de seus lares, nem mesmo plantar seus alimentos típicos era possível.

Não há, talvez, forma mais cruel de aniquilar uma etnia inteira do que impossibilitar sua forma de viver e dela remover, pouco a pouco, a oportunidade de utilizar seu saber acumulado, que por vezes é um saber milenar. É por essa razão que em um país como o Brasil, uma instituição como a Funai é extremamente importante. De igual forma, é por essa razão que o já referido Plano Emergencial é assaz valoroso. Segundo Santi, a inobservância de uma aplicação adequada desse plano teve uma consequência nefasta.

O Plano Emergencial era um conjunto de medidas antecipatórias indispensáveis à viabilidade de Belo Monte. Envolvia o fortalecimento da Funai, um plano robusto de proteção territorial e o programa de etnodesenvolvimento. $\mathrm{O}$ fortalecimento da Funai não foi feito. O plano de proteção não iniciou. E o plano de etnodesenvolvimento? Foi substituído por ações do empreendedor à margem do licenciamento, por meio das quais os indígenas foram atraídos para Altamira, para disputar nos balcões da Norte Energia toda a sorte de mercadoria, com os recursos destinados aos programas de fortalecimento. (...)

Essa ação da Norte Energia se deu à margem do licenciamento. Se os estudos previram que Belo Monte seria de altíssimo risco, e trouxeram uma série de medidas necessárias, e o que o empreendedor fez foi isso... A que conclusão podemos chegar? Se existiam medidas para mitigar o altíssimo risco que Belo Monte trazia para os indígenas, e essas políticas não foram feitas, e em substituição a elas o que foi feito foi uma política marginal de instigação de consumo, de ruptura de vínculo social, de desprezo à tradição, de forma que os indígenas fossem atraídos para o núcleo urbano pelo empreendedor e jogados no pior da nossa cultura, que é o consumismo. E no consumismo dos piores bens, que é a Coca-Cola, que é o óleo... Ou seja: todos os estudos foram feitos para quê? Tanto antropólogo participando para, na 
hora de implementar a política, o empreendedor criar um balcão direto com o indígena, fornecendo o que lhe der na telha? O que aconteceu em Belo Monte: o impacto do Plano Emergencial, que ainda não foi avaliado, até esse momento, foi maior do que o próprio impacto do empreendimento. A ação do empreendedor foi avassaladora. Então, de novo, qual é o impacto de Belo Monte? O etnocídio indígena. (BRUM, 2014, s./p.)

Dessarte, as ações da Norte Energia, empresa responsável pela construção de Belo Monte, aliada ao descaso de grande parte do poder público, resultou no que se pode verificar enquanto um verdadeiro etnocídio indígena. O que se percebe é que essa consequência nefasta se manifesta, na atual conjuntura capitalista moderna, não enquanto uma tragédia, mas como um preço que setores do governo e do empresariado estão dispostos a pagar em nome do lucro e do progresso.

Boaventura de Souza Santos e Maria Paula Meneses (2010c, p. 16), ao refletirem sobre o fenômeno da dominação epistemológica, escrevem que a “intervenção se deu de forma tão profunda e, sempre que necessário, suprimiu todas as práticas sociais e conhecimento que contrariassem os interesses que ela servia. Nisso consistiu o epistemicídio (...)". Os povos autóctones foram usurpados de suas tradições, conhecimentos e identidade, prática que acabou por consolidar, em contrapartida, o privilégio epistêmico do branco europeu e totalizante. Segundo Sousa e Meneses (2010c, p. 49),

[...] o mundo é um complexo mosaico multicultural. Todavia, ao longo da modernidade, a produção do conhecimento científico foi configurada por um único modelo epistemológico, como se o mundo fosse monocultural, o qual descontextualizou o conhecimento e impediu a emergência de outras formas de saber não redutíveis a esse paradigma. Assistiu-se, assim, a uma espécie de epistemicídio, ou seja, à destruição de algumas formas de saber locais, à inferiorização de outras, desperdiçando-se, em nome dos desígnios do colonialismo, a riqueza de perspectivas presentes na diversidade cultural e nas multifacetadas visões do mundo por elas protagonizadas. 
Conforme demonstrado, a epistemologia dominante é responsável por invisibilizar e desconsiderar outros saberes que não aquele racional, instrumental e ocidental. Mas, para além disso, esse conhecimento hegemônico técnicocientífico legitima a apropriação dos recursos naturais e a dominação da natureza em detrimento do lucro de poucos. Ou seja, a racionalidade cartesiana que embasa o projeto civilizatório da modernidade e a sua noção de desenvolvimento traz consigo, necessariamente, exclusão e perda. E essa perda transcende valores pecuniários e econômicos: trata-se de perda cultural, natural, social e política trata-se da perda da vida. À razão indolente, porém, Boaventura de Sousa Santos faz uma proposta de superação, que é a aposta do presente trabalho, a fim de superar situações similares à de Belo Monte. É sobre essa proposta que trata o próximo capítulo.

\section{O COSMOPOLITISMO SUBALTERNO, A HERMENÊUTICA DIATÓPICA E A DEFESA DA ECOLOGIA DE SABERES}

Segundo Boaventura de Sousa Santos, a complexidade de alguns direitos, como os direitos humanos, reside no fato de que eles podem ser concebidos tanto como forma de localismo globalizado como forma de cosmopolitismo. Isto é, como globalização hegemônica ou como globalização contra-hegemônica. O objetivo deste capítulo é verificar as possibilidades de potencializar a efetivação de direitos a partir de um entendimento desde a hermenêutica diatópica, enquanto manifestação de um cosmopolitismo insurgente, reconhecendo que há diferentes formas de saber coexistentes no mundo e que devem ser respeitadas. A aposta é, portanto, o que o autor perfilha como uma ecologia de saberes que seja capaz de ultrapassar a ideia de monocultura da mente e de racionalidade indolente. 
No que diz respeito aos direitos humanos, o autor entende que enquanto forem concebidos como universais, os direitos humanos tendem a operar como localismo globalizado e serão sempre um instrumento do "choque de civilizações", isto é, serão utilizados como uma arma do Ocidente contra o resto do mundo (SANTOS, B., 2002, s./p.), segue o autor,

\begin{abstract}
A sua abrangência global será obtida à custa da sua legitimidade local. Para poderem operar como forma de cosmopolitismo, como globalização de-baixo-para-cima ou contra-hegemónica, os direitos humanos têm de ser reconceptualizados como multiculturais. O multiculturalismo, tal como eu o entendo, é pré-condição de uma relação equilibrada e mutuamente potenciadora entre a competência global e a legitimidade local, que constituem os dois atributos de uma política contrahegemónica de direitos humanos no nosso tempo.
\end{abstract}

Sabe-se que os direitos não são universais na sua aplicação. Eles são, segundo Santos, consensualmente identificados em quatro regimes internacionais de aplicação: o europeu, o inter-americano, o africano e o asiático. Destaca o autor, porém, que apesar de todas as culturas tenderem a considerar os seus valores máximos como os mais abrangentes, apenas a cultura ocidental tende a tomá-los como universais. E por essa razão, “a questão da universalidade dos direitos humanos trai a universalidade do que questiona pelo modo como o questiona. Por outras palavras, a questão da universalidade é uma questão particular, uma questão específica da cultura ocidental" (SANTOS, B. 2002, s./p.).

A proposta, neste capítulo final, é pensar o tema da proteção dos direitos como revelador da política enquanto cultura política, o que se pode observar nos capítulos anteriores. Para Boaventura de Sousa Santos (2010a, p. 21), significa compreender a existência de uma tensão entre monoculturas hegemônicas e aspirações de interculturalidade, isto é, confrontar concepções hegemônicas e contra-hegemônicas através de um diálogo que ultrapasse o universalismo 
abstrato colonial. Para tanto, busca-se, através de diálogos interculturais sob diferentes concepções de dignidade da pessoa humana, um universalismo concreto, construído de baixo para cima.

Para a efetiva transformação dos direitos humanos em um projeto cosmopolita insurgente, Boaventura de Sousa Santos enumera cinco premissas, quais sejam, a) a superação do debate sobre universalismo e relativismo cultural; b) todas as culturas possuem concepções de dignidade humana, ainda que nem todas elas a concebam em termos de direitos humanos; c) todas as culturas são incompletas e problemáticas nas suas concepções de dignidade humana; d) nenhuma cultura é monolítica, e todas suportam versões diferentes de dignidade humana; e e) todas as culturas tendem a distribuir as pessoas e os grupos sociais entre dois princípios competitivos de presença hierárquica, quais sejam, igualdade e diferença (SANTOS, B., 2010a, pp. 445-446).

Essas são as premissas para o início de um diálogo intercultural sobre a dignidade humana e que se constitui enquanto um caminho possível para avançar na concepção de direitos humanos que rompa com a platônica ideia de um universalismo e que, com os pés no chão, possibilite uma organização em torno de sentidos locais. Se essas premissas são aceitas, a porta para o diálogo é aberta para se falar no ponto central do presente artigo, o reconhecimento da hermenêutica diatópica como condição de possibilidade para o cosmopolitismo jurídico e o avanço na proteção efetiva dos direitos humanos.

Em se tratando de um diálogo intercultural, a troca operada não se dá tão somente no plano dos saberes, "mas também entre diferentes culturas, ou seja, entre universos de sentido diferentes e, em grande medida, incomensuráveis. Tais universos de sentido consistem em constelações de topoi fortes" (SANTOS, B. 2002, s./p.). Os topoi se constituem enquanto os lugares comuns retóricos mais abrangentes de uma determinada cultura. A compreensão de uma determinada 
91 InterAção

cultura a partir dos topoi de outra cultura pode se manifestar enquanto uma tarefa bastante difícil, mas não impossível.

Ao se partir de um pressuposto de que não se trata de tarefa impossível é que ganha força a ideia de uma hermenêutica diatópica,

\begin{abstract}
A hermenêutica diatópica baseia-se na ideia de que os topoi de uma dada cultura, por mais fortes que sejam, são tão incompletos quanto a própria cultura a que pertencem. Tal incompletude não é visível do interior dessa cultura, uma vez que a aspiração à totalidade induz a que se tome a parte pelo todo. O objectivo da hermenêutica diatópica não é, porém, atingir a completude um objectivo inatingível - mas, pelo contrário, ampliar ao máximo a consciência de incompletude mútua através de um diálogo que se desenrola, por assim dizer, com um pé numa cultura e outro, noutra. Nisto reside o seu carácter dia-tópico. (SANTOS, B., 2002, s./p.).
\end{abstract}

Em outras palavras, a luta pelos direitos humanos e pela defesa e promoção da dignidade humana é mais que um exercício intelectual, é uma prática resultante de uma entrega moral, afetiva e emocional somente possível a partir de uma identificação profunda com os postulados culturais inscritos na personalidade e nas formas básicas de socialização (SANTOS, B., 2010a, p. 447). O exemplo de hermenêutica diatópica trazido por Santos é "a que pode ter lugar entre o topos dos direitos humanos na cultura ocidental, o topos do dharma na cultura hindu e o topos da umma na cultura islâmica".

Não é o objetivo do presente artigo adentrar pormenorizadamente nos pontos específicos de divergência, tampouco fazer uma defesa inconteste da hermenêutica diatópica, até mesmo porque o multiculturalismo poderia servir como uma nova roupagem às velhas práticas coloniais hegemônicas. O que se pretende é apresentar uma possibilidade, a qual depende, para seu melhor aproveitamento, do respeito a duas premissas interculturais que devem ser aceitas pelos grupos envolvidos no desenvolvimento desta modalidade hermenêutica, a saber: 
O primeiro pode formular-se assim: das diferentes versões de uma dada cultura, deve ser escolhida aquela que representa o círculo mais amplo de reciprocidade dentro dessa cultura, a versão que vai mais longe no reconhecimento do outro. (...) $\mathrm{O}$ segundo imperativo intercultural pode ser enunciado do seguinte modo: uma vez que todas as culturas tendem a distribuir pessoas e grupos de acordo com dois princípios concorrentes de pertença hierárquica, e, portanto, com concepções concorrentes de igualdade e diferença, as pessoas e os grupos sociais têm o direito a ser iguais quando a diferença os inferioriza, e o direito a ser diferentes quando a igualdade os descaracteriza. (SANTOS, B. 2002, s./p.).

Ainda que este último seja um imperativo bastante difícil de atingir e de manter, há alguns estados que caminham no sentido de se aproximarem dele em alguns aspectos. Segundo Sartre, antes de ser concretizada, uma ideia tem uma estranha semelhança com a utopia. É o que se pretende no presente artigo. Ainda que possa parecer bastante distante da realidade, sobretudo no domínio americano, há experiências que permitem expectar a utilização da hermenêutica diatópica no plano internacional.

Se essa possibilidade começa a ser observada, ainda que timidamente, no plano internacional, é possível propor o reconhecimento dos direitos humanos das populações vulneráveis também no plano nacional. Ainda que a cultura dos povos indígenas - tema do presente trabalho - se diferencie da cultura ocidental de herança europeia, é preciso reconhecer as suas particularidades e respeitar seu topoi ${ }^{8}$.

Verifica-se, portanto, um forte potencial de aprimoramento para a efetivação dos direitos humanos dos povos tradicionais desde uma compreensão a partir da hermenêutica diatópica desses. É na ideia de incompletude de todas as culturas e no aprofundamento da consciência dessa incompletude que é feita

\footnotetext{
8 Destaca-se a despretensão do presente trabalho em aprofundar o estudo acerca da definição do topoi dos povos tradicionais referidos no presente trabalho, quais sejam, os povos tradicionais que habitam a Bacia do Xingu, na região Norte do Brasil. Apenas faz-se a referência como proposta do reconhecimento de uma cultura diversa da reconhecida razão indolente instrumental que orienta o pensamento moderno de traços coloniais.
} 
a diversidade cultural, social e epistemológica do mundo: é nessa consciência que reside a nova gramática do tempo (SANTOS, B. 2010a, p. 21).

Percebe-se, portanto, que a razão que orienta a utilização da hermenêutica diatópica como solução de conflitos jurídicos consiste enquanto uma verdadeira forma de cosmopolitismo subalterno. Isso porque se consolida enquanto uma possibilidade de resolução que respeita os saberes e a cultura de todos os povos. Em assim sendo, vislumbra-se, ao mesmo tempo, a manifestação de um respeito mútuo que orienta as relações entre diferentes formas de saber. À possibilidade de coexistência de saberes e reconhecimento da importância e validade de outros saberes que não apenas a racionalidade moderna de matriz europeia Boaventura de Sousa Santos chama de Ecologia de Saberes (SANTOS, B., 2010b, p. 54).

Desde essa forma de conceber o conhecimento, e da aposta em sua aplicação, conclui-se, do presente capítulo, que a conjugação das ideias de hermenêutica diatópica enquanto condição de possibilidade para um cosmopolitismo subalterno se constitui enquanto um alento à aposta em uma ecologia de saberes, como forma de respeito a todas as culturas e de efetivação de direitos nos mais diversos planos e lugares.

\section{CONSIDERAÇÕES FINAIS}

A sociedade globalizada é permeada pelo paradigma da aceleração, e constitui-se enquanto um modelo organizacional completamente diverso de qualquer outro existente até então. $\mathrm{O}$ capitalismo moderno, as lógicas civilizatórias e coloniais nele atravessadas, se utiliza da razão instrumental indolente - para avançar dentro e para além dos limites nacionais. O fenômeno da globalização, porém, não pode ser considerado ensimesmadamente enquanto 
$94 \mid$ InterAção

bom ou ruim, o juízo de valor somente pode residir sobre as consequências de uma ou outra forma de globalização.

Na esteira do que refere Boaventura de Sousa Santos, a principal forma de globalização observada na atualidade é o globalismo localizado, orientado por uma racionalidade que se pauta por uma mentalidade monocultural. A potencialização dos efeitos coloniais nas dinâmicas organizacionais e relacionais hegemônicas recrudescem a violação dos direitos a populações em estado de vulnerabilidade, sobretudo porque tais processos são diretamente responsáveis pela invisibilidade, silenciamento e dominação de tais populações. É consabido que o direito está sempre atrasado em relação às transformações da sociedade, e por isso impõe-se a necessidade de pensar em possíveis soluções.

A efetividade da proteção de direitos certamente perpassa pela resposta do judiciário aos casos concretos. Todavia, tal resposta não pode ignorar toda a conjuntura moderna e desenvolvimentista que é condição de manutenção do silenciamento e exclusão dos saberes e tradições dos povos autóctones. Por isso, é preciso ultrapassar a racionalidade instrumental que orienta a tomada de decisões e o pensamento colonial que é tendência ao se pensar o direito a partir de uma matriz eurocêntrica. Trespassar a utilização da razão indolente e adentrar em um campo de diálogo com outras culturas é fundamental não apenas para o avanço na consolidação e efetivação de direitos de populações indígenas, mas para a preservação do patrimônio natural, histórico e cultural de um país tão rico em sociobiodiversidade, como o Brasil.

A hermenêutica diatópica se caracteriza, a partir da abordagem adotada no trabalho, enquanto complemento fundamental ao comprometimento com um reconhecimento do outro que conecte diferentes topoi, a fim de encontrar decisões com respeito à interculturalidade nos casos concretos. Ainda que o projeto pareça 
95 InterAção

utópico, verifica-se um embrião possível a partir das pesquisas acadêmicas que ocorrem simultaneamente em diversas localidades.

Assim, desde uma abordagem complexa, e sem a pretensão de concluir definitivamente sobre a temática, foi possível verificar que, a partir do compromisso com a consolidação de um cosmopolitismo subalterno orientado pela hermenêutica diatópica, é possível pensar em uma ecologia de saberes. A partir de então, vislumbra-se, no horizonte, a possibilidade da manifestação de decisões mais adequadas sob a lente dos direitos humanos, e que resguardem e protejam as particularidades de populações em situação de vulnerabilidade diante do fenômeno da globalização.

\section{REFERÊNCIAS}

ARAUJO, Luiz Ernani Bonesso de. O Direito da Sociobiodiversidade. In: TYBUSH, Jerônimo Siqueira; ARAUJO, Luiz Ernani Bonesso de; SILVA, Rosane Leal da (orgs.). Direitos Emergentes na Sociedade Global: Anuário do Programa de Pós-Graduação em Direito da UFSM. Ijuí: Unijuí, 2013;

BRUM, Eliane. Belo Monte: a anatomia de um etnocídio. El País. Entrevista com Thais Santi. Disponível em:

<http://brasil.elpais.com/brasil/2014/12/01/opinion/1417437633_930086.htm 1> Acesso em: 14 ago. 2016.

DEMO, Pedro. Complexidade e aprendizagem: a dinâmica não-linear do conhecimento. São Paulo: Atlas, 2008.

DUPAS, Gilberto. O mito do progresso: ou progresso como ideologia. 2. ed. São Paulo: Unesp, 2012.

DUSSEL, Enrique. Meditações anticartesianas sobre a origem do antidiscurso filosófico da modernidade. In: SANTOS, Boaventura de Sousa; MENESES, Maria Paula. (Orgs.). Epistemologias do Sul. São Paulo: Cortez, 2009. 
Europa, modernidade e eurocentrismo. In: A colonalidade do saber: eurocentrismo e ciências sociais. Perspectivas Latino-americanas. Edgardo Lander (org.). Buenos Aires: CLACSO, 2005.

MORIN, Edgar. Introdução ao pensamento complexo. 4. ed. Lisboa: Piaget, 2003.

MIGNOLO, Walter. A colonialidade de cabo a rabo: o hemisfério ocidental no horizonte conceitual da modernidade. In: LANDER, E. (Org.). A colonialidade do saber: eurocentrismo e ciências sociais. Perspectivas latino-americanas. Buenos Aires: Clacso, 2005. p. 71-103.

PORTO-GONÇALVES, Carlos Walter. A globalização da natureza e a natureza da globalização. Rio de Janeiro: Civilização Brasileira, 2006.

QUIJANO, Anibal. Colonialidade do poder e classificação social. In: SANTOS, Boaventura de Sousa; MENESES, Maria Paula. (Orgs.). Epistemologias do Sul. São Paulo: Cortez, 2010.

SALDANHA, Jânia Maria Lopes. A aplicação da margem nacional de apreciação pelas cortes de direitos humanos: desafios à internacionalização dos direitos humanos. In: REDIN, Giuliana; SALDANHA, Jânia Maria Lopes; SILVA, Maria Beatriz Oliveira da (Orgs.). Direitos Emergentes na Sociedade Global: Programa de Pós-Graduação em Direito da UFSM. Santa Maria: UFSM, 2016.

SANTOS, Boaventura de Sousa. A gramática do tempo: para uma nova cultura política. 3. ed. Coleção para um novo senso comum. V. 4. São Paulo: Cortez, 2010a.

As tensões da modernidade. 2002. Disponível em:

<http://www.dhnet.org.br/direitos/militantes/boaventura/boaventura4.html \#1>. Acesso em: 28 jul. 2016.

Para além do pensamento abissal: das linhas globais a uma ecologia de saberes. In: SANTOS, Boaventura de Sousa; MENESES, Maria Paula. (Orgs.). Epistemologias do Sul. São Paulo: Cortez, 2010b.

; MENESES, Maria Paula. (Orgs.). Epistemologias do Sul. São Paulo: Cortez, 2010c.

SANTOS, Milton. Por uma outra globalização: do pensamento único à consciência universal. 25. ed. Rio de Janeiro: Record, 2015. 
97 InterAção

WALSH, Catherine. Interculturalidad, plurinacionalidad y decolonialidad: las insurgências político-epistêmcas de refundar el Estado. Tabula Rasa. Bogotá Colombia, No.9: 131-152, julio-diciembre 2008. 